\title{
Application of EPC Management Model in Construction of Long-distance Pipeline Project
}

\author{
Yang An \\ China National Oil and Gas Exploration and Development Corporation (CNODC), Beijing 100034, \\ China \\ albertan82@gmail.com
}

Keywords: Long-distance pipe, EPC model, project construction.

\begin{abstract}
Long-distance pipeline has always played a significant role and kept its basic position in the West-East Gas Transmission and West-East Oil Supply programs in China. If natural gas or petroleum is not supported by pipeline, its transmission will be inevitably more dangerous to some extent. The study in this paper will focus on the macroscopic background and explore the relevant elements of EPC management model, so as to put forward the strategy for its application in the construction of long-distance pipeline project.
\end{abstract}

\section{Introduction}

Thanks to the rapid development of economy and science \& technology in China, the exploration and exploitation of petroleum and natural gas have reached a new level. Along with the increasing scale of relevant construction projects, the technical requirements of construction have been also increased to a certain level. Based on the characteristics of current pipeline transmission, the construction of long-distance pipeline projects has been improved to some extent, so as to further realize the flexible transmission through pipeline.

\section{Overview of Relevant Theories}

\subsection{Pipeline and Long-distance Pipeline}

First of all, pipeline refers to a transmission facility used to transport petroleum, natural gas and other fluids. To transport those objects, pipeline is employed mainly because of its high transmission capacity, small size, safety and sustainability. In terms of construction period, pipeline has relatively low construction cost, and short construction period, and is able to bring high benefits in the process of transmission.

Long-distance pipeline is a new way of long-distance transmission on the basis of pipeline across provinces, regions, rivers and lakes. Long-distance pipeline is characterized by large pipe diameter and long transmission distance, etc.

\subsection{EPC Management Model}

EPC stands for Engineering Procurement Construction. To be specific, it means that an investor or several EPC general contractors undertake the engineering, procurement, construction and operation of the whole project, so as to complete the works ready for service. Actually, this model utilizes the matrix structure. The contract is performed by work team, and then project manager is responsible for the whole work team. After the performance of the contract is completed, the work team will be dissolved. EPC model has some requirements for the quality of members in the whole project. Hence, EPC model is more suitable for the projects with long construction period and complex technology in every respect. 
Table 1. China's Major Oil Pipeline Projects

\begin{tabular}{|c|c|c|c|c|c|c|}
\hline No & Name & Developer & $\begin{array}{l}\text { Starting } \\
\text { Year }\end{array}$ & $\begin{array}{l}\text { Completion } \\
\text { Year }\end{array}$ & $\begin{array}{l}\text { Transmission } \\
\text { Medium }\end{array}$ & $\begin{array}{c}\text { Length } \\
(\mathrm{KM})\end{array}$ \\
\hline 1 & $\begin{array}{l}\text { Yongqing-Tangshan-Qinhuangdao } \\
\text { Natural Gas Pipeline }\end{array}$ & $\begin{array}{l}\text { China Natural } \\
\text { Gas Co., Ltd. }\end{array}$ & 2007 & 2009 & Natural gas & 324 \\
\hline 2 & $\begin{array}{l}\text { West-East Gas Transmission } \\
\text { Pipeline No. } 2\end{array}$ & $\begin{array}{c}\text { Pipeline } \\
\text { Construction } \\
\text { Administration } \\
\text { Department }\end{array}$ & 2008 & 2011 & Natural gas & 9800 \\
\hline 3 & $\begin{array}{l}\text { Sebei-Xining-Lanzhou Natural } \\
\text { Gas Pipeline Duplex }\end{array}$ & $\begin{array}{c}\text { Pipeline } \\
\text { Construction } \\
\text { Administration } \\
\text { Department } \\
\end{array}$ & 2008 & 2009 & Natural gas & 932 \\
\hline 4 & $\begin{array}{l}\text { Shaanxi-Beijing Pipeline No. } 3 \\
\text { (Jingbian-Qinhuangdao) }\end{array}$ & $\begin{array}{c}\text { Pipeline } \\
\text { Construction } \\
\text { Administration } \\
\text { Department }\end{array}$ & 2010 & 2011 & Natural gas & 1359 \\
\hline 5 & $\begin{array}{l}\text { West-East Gas Transmission } \\
\text { Pipeline No. } 3 \\
\text { (Lunnan-Zhongwei) }\end{array}$ & $\begin{array}{c}\text { Pipeline } \\
\text { Construction } \\
\text { Administration } \\
\text { Department }\end{array}$ & 2011 & 2012 & Natural gas & 2006 \\
\hline 6 & $\begin{array}{c}\text { Geermu-Lhasa Natural Gas } \\
\text { Pipeline }\end{array}$ & $\begin{array}{c}\text { Pipeline } \\
\text { Construction } \\
\text { Administration } \\
\text { Department }\end{array}$ & 2010 & 2012 & Natural gas & 1200 \\
\hline 7 & $\begin{array}{l}\text { Longgang Outbound Transmission } \\
\text { Pipeline (Longgang-Guizhou) }\end{array}$ & $\begin{array}{c}\text { Pipeline } \\
\text { Construction } \\
\text { Administration } \\
\text { Department }\end{array}$ & & 2012 & Natural gas & 655 \\
\hline 8 & $\begin{array}{l}\text { Northeastern Natural Gas Pipeline } \\
\text { (Shenyang-Qinhuangdao Section) }\end{array}$ & $\begin{array}{c}\text { Pipeline } \\
\text { Construction } \\
\text { Administration } \\
\text { Department }\end{array}$ & 2009 & & Natural gas & $\begin{array}{c}766 \\
(400)\end{array}$ \\
\hline
\end{tabular}

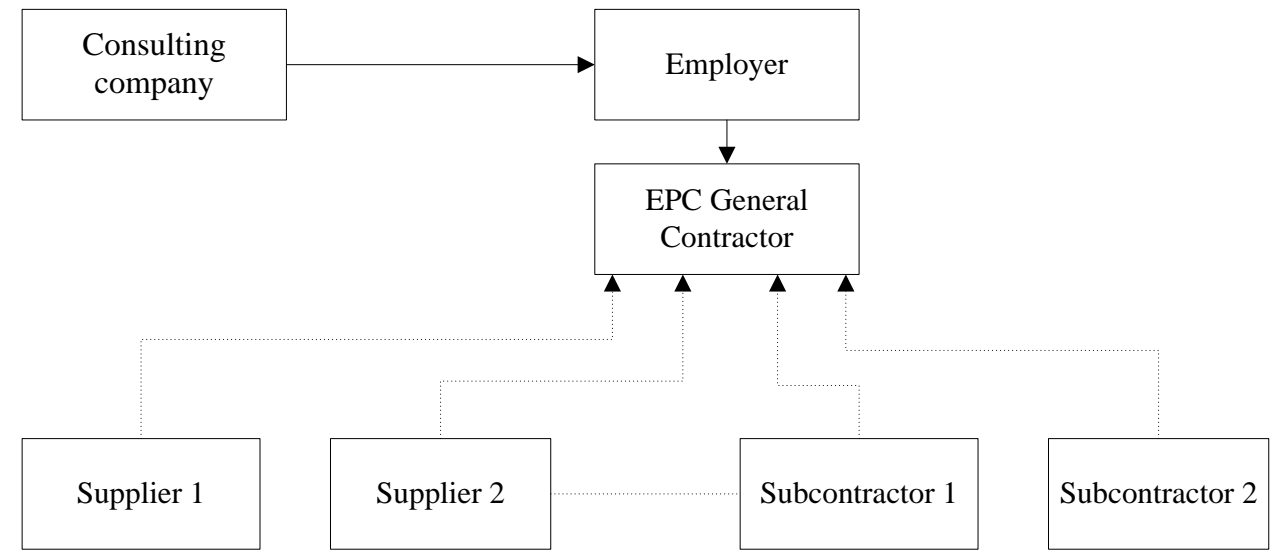

Fig.1 The EPC Model Structure

\section{Application of EPC Project Management Model in Construction of Long-distance Pipeline Project}

\subsection{Construction of West Pipeline}

In the west pipeline project, China National Petroleum Corporation (CNPC) implemented the EPC management model for the first time. In the process of construction and development, the project construction management system was gradually established with the Employer as the core and the 
EPC as the subject to exercise the right of management in the project. At a macroscopic level, CNPC carried out the EPC general contracting for the first time, so a lot of construction teams involved did not know much about this contracting model. To help all parties understand this model extensively to the maximum, the Employer, supervision unit and EPC involved in the west pipeline project jointly developed the coordination manual through corresponding discussion and study, and applied it in the construction of the project. The coordination manual gave a detailed description of actual management model in the pipeline construction project, and effectively specified the work relations and scope of responsibilities in all respects, so as to effectively guarantee the maximization of construction results in the west pipeline processed and crude oil system project.

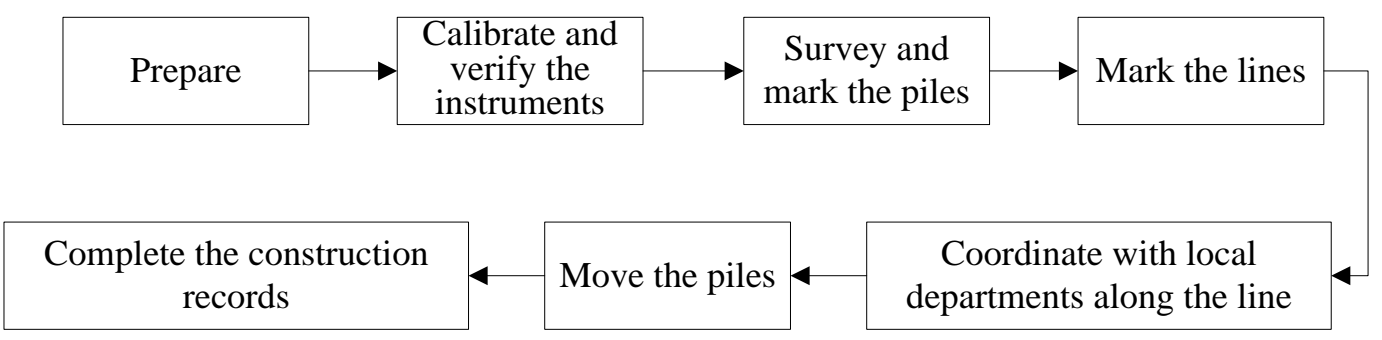

Fig. 2 West Pipeline Construction Flow Chart

\subsection{Construction of Lanzhou-Yinchuan Pipeline}

The construction of Lanzhou-Yinchuan Pipeline was most remarkably significant to realizing the network of three main gas fields in the western region to the maximum, that is, Qinghai Gas Field, Changqing Gas Field and Tarim Gas Field. In this way, it could realize the mutual supplementation and complementation among these three gas fields. With regard to the principles of organization, the EPC project of Lanzhou-Yinchuan Pipeline persisted in taking the pipeline bureau as the legal person to undertake the general contracting of the whole project. On behalf of the pipeline bureau, project department could perform the rights and obligations specified in the contract. In the EPC project, project department was responsible for the management of the whole project, and often utilized subcontract to manage the subcontracting of engineering, procurement and construction. Hence, the relationship between general contractor and subcontractors was never changed no matter what membership existed in the implementation of the project. To give full play to the advantages of EPC general contracting, the divisions of project department must reinforce their management functions and realize their coordinated operation.

\section{Analysis on Existing Problems in Long-distance Pipeline Project with EPC Model in China}

\subsection{Distribution of Responsibilities}

Now, there is not any specific and scientific pattern of operation for EPC model, so it may be practiced in various forms, which cause the disagreements of the Employer and general contractor to some extent. For instance, the EPC general contract for the west pipeline project and the West-East Gas Transmission Line No. 2 project in China was signed when the project was about to complete. Hence, the constraining power of contract is inevitably limited and affected.

\subsection{Project Supervision}

Project supervision should be introduced in a scientific and timely manner. Now, most of domestic and overseas long-distance pipeline projects belong to large companies with strong capability of general contracting and independent management system. However, the project consulting companies are developed less satisfactorily, and still clearly rely on the operation mode of Supervision Company.

\subsection{Talents}

As long-distance pipeline project is still young, there are not sufficient comprehensive talents to provide supports in the process of engineering, procurement, construction and mining service. Hence, the disconnection of engineering, procurement and construction is very clear inside the EPC Company in China, which affects the overall development of the EPC Company to some extent. Additionally, the accumulated gap is constantly widening between information technology and empirical data. 
Especially in some large high-end projects, management software and system have not become the effective tools during their construction. In addition to lack of historical engineering data, there are not certain standards for implementation of new projects.

\section{Application of EPC Mode in Construction of Long-distance Pipeline Project}

\subsection{Project Management Planning}

First of all, it is necessary to determine the basic organizational structure, which contains multiple elements in a project. The organizational structure has strong influence on the implementation of the whole project, and normally relies on the corresponding chart for description. In the process of project management, it is necessary to break down the objectives, involving investment, schedule, quality and safety objectives. During breakdown of these objectives, all kinds of focused measures for technology, economy, organization and management may be taken to guarantee the realization of the general objective to the maximum.

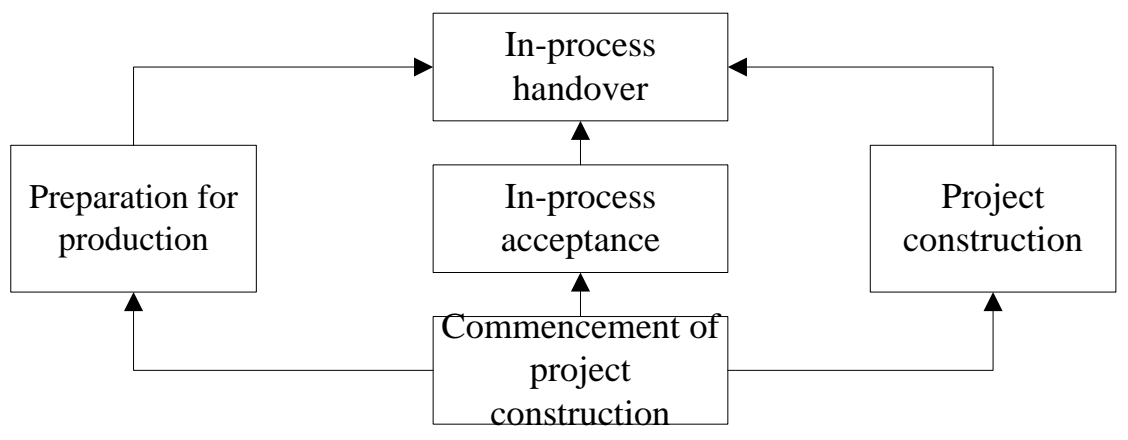

Fig. 3 EPC Project Construction Phase

Second, for breakdown of project management, it is necessary to observe the environment of the whole project carefully in the preparation, and then make corresponding plans and compose the feasibility study report and the report on general ideas, so as to truly implement the relevant matters and work plans and guarantee the distribution of work to personnel in the end.

\subsection{Contract Management}

Contract Performance

Project manager must organize relevant personnel to disclose the contracts. In this process, it is necessary to classify the contracts in terms of risk into extremely risky contracts, highly risky contracts and common contracts. In the specific process of implementation, external factors should be also taken into account comprehensively to guarantee the dynamic adjustment of risk level. In the process of implementation, if any problem is discovered, measures should be taken to deal with it in a timely manner. Meanwhile, good information exchange with the contract management department at higher level should be guaranteed. Both parties to the project should collect the valid evidences immediately, and well handle the claims and counterclaims at construction site. If a contract is terminated, the relevant divisions of project department should report the actual condition to the superior in written form.

Signing Management

The relevant division of project department should submit the documents for signing to the Employer before the deadline agreed in the contract. If the deadline is not agreed in the contract, the documents for signing should be submitted to the Employer in a timely manner, and the formalities for signing should be handled based on the actual needs of the Employer. The personnel handling this submission at the site should gather the documents, fill the signing form, and carry out the effective rechecking. If any special condition occurs, if the contract issuing party has requirements, the documents should be submitted to the chief economic engineer for examination and approval.

Contract management inevitably involves the intermediate settlement, so it is necessary to prepare the intermediate settlement at such time and in such form as agreed in the contract. If there is not any agreement on intermediate settlement in the contract, it is necessary to prepare the intermediate 
settlement of the project based on the schedule of the whole project and the required construction period. The basis for preparation of EPC intermediate settlement involves a lot of information, including bidding documents and bid documents, monthly schedule, examination and approval form, budget for shop drawings, and shop drawings, etc.

\subsection{Engineering Management}

To engineering management, the most important work is detailed design. The specific contents are as follows:

To each profession, it is necessary to effectively optimize and arrange the equipment and pipeline involved in its work. Before preparing the comprehensive shop drawings, it is necessary to submit the documents to the designer of the EPC route. In this way, relevant people involved will give some comments and point out specific issues conveniently. After reviewing all the contents, the overall shop drawing can be designed. Many parties should take part in the process of designing shop drawings, and must carry out the actual activities under the leadership of the EPC general contractor's design department.

\subsection{Procurement Management}

The EPC general contractor must carry out the corresponding survey and evaluation with regard to the suppliers of materials and equipment, which is mainly conducted by project department. The procurement management department at higher level should review many matters in the process of procurement. If there are quality problems or violations of contract, it is necessary to carry out the evaluation again. The contents of evaluation are directly related to the quality of product and the scale of production. In the EPC procurement, the following documents are involved:

Request Plan for Quality of Project Materials

At this level, it mainly includes the request plan for total quantity of materials and the request plan for monthly quantity of materials, etc. During the regular work, professional technicians of a project should classify the project materials based on their specification \& model, material, quantity, and date of arrival. If any content is changed, it is necessary to give a sufficient description about how to make the change.

\section{Project Material Procurement Plan}

In an EPC project, project department should make scientific and reasonable identifications on the procurement plan based on the relevant plans of the project, the inventory, market demand and consumption, and must manage the procurement documents independently. In the process, it is necessary to notice that EPC general contractor only reviews the qualification of suppliers and evaluates the effectiveness of documents.

\section{Conclusion}

In this paper, the theories related to EPC are discussed on the basis of practical experience in long-distance pipeline project management, while the current development of EPC at home and abroad is analyzed. Compared to the practical achievements in developed countries, China still needs to make improvements in the management model of long-distance pipeline project, including adjustment of structure and improvement of project management level. In the future development, the supervision by government should be strengthened to effectively improve the project management level with EPC general contracting.

\section{References}

[1]. Xie Jianping. Research on Application of PMT+PMC+EPC Management Model in the Construction of CNPC's Long-distance Pipeline Project [D]. Tianjin Polytechnic University, 2010.

[2]. Xing Zhangang. Application of EPC general contracting model in construction of domestic long-distance pipeline [J]. Management Observer, 2009(7):216-217. 
[3]. Yang Jun. Study on application of EPC model in construction of long-distance pipeline project [J]. China Chemical Trade, 2013(6):414-414.

[4]. Pan Huibin. Research on Risk Management under the EPC Model of Long-distance Pipeline [D]. Tianjin University, 2008.

[5]. Guo Chen, Yi Shuping, Gao Qingxuan et al. Integrated HSE Risk Management Model of Long Distance Transmission Pipeline Construction Projects [J]. Industrial Engineering and Management, 2009, 14(5):129-134.

[6]. Gao Peng, Jia Xu and Zhang Hao. Risks in EPC contract management for construction of domestic long- distance pipeline project and their prevention [J]. Chemical Enterprise Management, 2013(10):15-15.

[7]. Qi Jingbin, Wang Jiangyu, Wang Zhiyong et al. Analysis on the change of domestic long-distance pipeline construction project with EPC model [J]. Value Engineering, 2013, 32(5):52-54.

[8]. Hou Zhiqiang. Study on construction management of long-distance pipeline under EPC model [J]. Global Market, 2017(6):253-253.

[9]. Chi Hongjian. Study on the construction management models for long-distance oil \& gas pipeline project in China [J]. International Petroleum Economics, 2012(11):83-87.

[10]. Di Jing and Yuan Jie. Cost management of long-distance pipeline project under the EPC model [J]. Engineering Technology, 2016(1):00077-00078. 